Thomas JJ, Ghazizadeh S, Masoero E.

Kinetic mechanisms and activation energies for hydration of standard and highly reactive forms of $\beta$-dicalcium silicate (C2S).

Cement and Concrete Research 2017, 100, 322-328.

\section{Copyright:}

(C) 2017. This manuscript version is made available under the CC-BY-NC-ND 4.0 license

DOI link to article:

https://doi.org/10.1016/i.cemconres.2017.06.001

Date deposited:

$13 / 06 / 2017$

Embargo release date:

02 August 2018

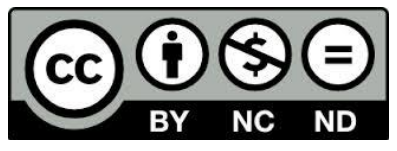

This work is licensed under a

Creative Commons Attribution-NonCommercial-NoDerivatives 4.0 International licence 


\title{
Kinetic mechanisms and activation energies for hydration of standard and highly reactive forms of $\beta$-dicalcium silicate $\left(\mathrm{C}_{2} \mathrm{~S}\right)$
}

\author{
Jeffrey J. Thomas ${ }^{\mathrm{a}, *}$, Sam Ghazizadeh ${ }^{\mathrm{b}}$, Enrico Masoero ${ }^{\mathrm{c}}$ \\ ${ }^{a}$ Schlumberger-Doll Research, Cambridge, MA 02139, U.S.A. \\ ${ }^{b}$ University College London, Department of Civil, Environmental 83 Geomatic Engineering, \\ London, WC1E 6BT, U.K. \\ ${ }^{c}$ Newcastle University, School of Civil Engineering and Geosciences, NE1 7RU, Newcastle \\ upon Tyne, U.K.
}

\begin{abstract}
The activation energy for hydration of $\beta-\mathrm{C}_{2} \mathrm{~S}$ paste was measured as a function of hydration time using a calorimetric method and was found to depend on the surface area and reactivity of the powder as well as on the addition of sodium silicate. For neat paste made with standard $\beta-\mathrm{C}_{2} \mathrm{~S}$ (similar to that found in portland cement), the activation energy is approximately $32 \mathrm{~kJ} / \mathrm{mol}$ and is constant with time. For neat paste made with reactive $\beta-\mathrm{C}_{2} \mathrm{~S}$ (calcined at lower temperature and with high surface area), the activation energy is about $55 \mathrm{~kJ} / \mathrm{mol}$ and is also constant with time. This large difference in activation energy reflects a difference in the rate-controlling step for hydration. After investigating the effects of sodium silicate and synthetic calcium-silicate-hydrate on the kinetics, we hypothesize that the lower activation energy represents $\mathrm{C}_{2} \mathrm{~S}$ dissolution, while the higher value represents nucleation and growth of hydration product.
\end{abstract}

Keywords: hydration, kinetics, dicalcium silicate, activation energy

${ }^{*}$ Corresponding author

Email addresses: jthomas39@slb.com (Jeffrey J. Thomas ), s.ghazizadeh@ucl.ac.uk (Sam Ghazizadeh), enrico.masoero@newcastle.ac.uk (Enrico Masoero) 


\section{Introduction}

Dicalcium silicate $\left(\mathrm{C}_{2} \mathrm{~S}\right)$ constitutes $15-30 \%$ of modern type-I ordinary portland cement (OPC) clinker, where it exists as the mineral belite, an impure form of the $\beta$ polymorph of $\mathrm{C}_{2} \mathrm{~S}$. Belite forms similar hydration products as the main cement mineral alite (impure tricalcium silicate, $\mathrm{C}_{3} \mathrm{~S}$ ), and, once well reacted, belite-rich cements have excellent mechanical properties. In addition, $\mathrm{C}_{2} \mathrm{~S}$ formation requires less limestone and lower calcination temperatures than $\mathrm{C}_{3} \mathrm{~S}$, so belite-rich cements may have the potential to reduce the carbon footprint of portland cement $[1,2]$. However, $\mathrm{C}_{2} \mathrm{~S}$ tends to be much less reactive than $\mathrm{C}_{3} \mathrm{~S}$. This leads to a slower development of mechanical properties that limits the extent to which belite can substitute for alite in cement clinker. Therefore, accelerating the hydration of $\beta-\mathrm{C}_{2} \mathrm{~S}$ is a strategic objective toward the development of more sustainable cements $[3,4]$.

Reactive forms of $\mathrm{C}_{2} \mathrm{~S}$ can be synthesized using a variety of methods, including sol gel processing [5], evaporative decomposition [6], thermal decomposition $[7,8]$, and the Pechini process $[9,10,11]$. It is also possible to increase reactivity by mechanical action [12]. The key seems to be to increase the surface area of the powder, which also has a strong effect on the reactivity of $\mathrm{C}_{3} \mathrm{~S}$ and alite $[13,14,15]$.

The effects of a variety of chemical additives on the hydration of $\beta-\mathrm{C}_{2} \mathrm{~S}$ have been explored, with the general finding that $\beta-\mathrm{C}_{2} \mathrm{~S}$ is much less sensitive to additives than $\mathrm{C}_{3} \mathrm{~S}$ [16]. In particular, salts such as $\mathrm{CaCl}_{2}$ that are effective in accelerating $\mathrm{C}_{3} \mathrm{~S}$ tend to be ineffective or retarding for $\beta-\mathrm{C}_{2} \mathrm{~S}$ [17]. A recent study showed that a high concentration of $\mathrm{KOH}(8 \mathrm{M})$ could significantly accelerate the hydration of $\beta-\mathrm{C}_{2} \mathrm{~S}$ [18].

In this study, we focus on understanding the hydration mechanisms and ratecontrolling steps for $\beta-\mathrm{C}_{2} \mathrm{~S}$ hydration. We compare the hydration of $\beta-\mathrm{C}_{2} \mathrm{~S}$ with a lower surface area similar to that of portland cement to the hydration of much more reactive $\beta-\mathrm{C}_{2} \mathrm{~S}$ formed using the Pechini chemical synthesis process, which is a straightforward and reliable method of making small batches of phase-pure 
$\beta-\mathrm{C}_{2} \mathrm{~S}$ with a range of surface areas and reactivity [10].

We also explore the effects of sodium metasilicate and synthetic calciumsilicate-hydrate $(\mathrm{C}-\mathrm{S}-\mathrm{H})$, two additives that have the potential to accelerate the hydration of $\beta-\mathrm{C}_{2} \mathrm{~S}$ and also to shed light on the hydration process. Sodium metasilicate is an effective accelerator for ground granulated blast furnace slag. It raises the $\mathrm{pH}$ of the pore solution, which can increase dissolution rates, and provides silicate ions that may increase early $\mathrm{C}-\mathrm{S}-\mathrm{H}$ formation. Synthetic $\mathrm{C}-\mathrm{S}-$ $\mathrm{H}$ has been shown to accelerate the hydration of $\mathrm{C}_{3} \mathrm{~S}, \mathrm{OPC}$, and alkali-activated slag pastes $[19,20]$. The $\mathrm{C}-\mathrm{S}-\mathrm{H}$ operates by a seeding effect, providing additional nucleation sites for hydration product to form [19]. Therefore, it would be

expected to be most effective when nucleation and growth is the rate controlling step.

The hydration kinetics of the $\beta-\mathrm{C}_{2} \mathrm{~S}$ pastes are evaluated using isothermal calorimetry at temperatures ranging from $30^{\circ} \mathrm{C}$ to $85^{\circ} \mathrm{C}$. In particular, we employ a recently developed calorimetric method of measuring the apparent activation energy as a function of time [21]. We find that the activation energy depends on both the reactivity of the powder and on the presence of the additives. The activation energy values tend to stabilize around values of either 32 $\mathrm{kJ} / \mathrm{mol}$ or $55 \mathrm{~kJ} / \mathrm{mol}$, and we interpret these values as reflecting different rate controlling steps for the hydration process.

\section{Materials and Methods}

\section{1. $C_{2} S$ powders}

Four different samples of pure $\beta-\mathrm{C}_{2} \mathrm{~S}$ were used for this study (see Table 1). Two powders were obtained from Construction Technology Laboratories (Skokie, IL) and were manufactured in the standard manner by hightemperature calcination of a stoichiometric mixture of $\mathrm{CaO}$ and $\mathrm{SiO}_{2}$. The resulting $\mathrm{C}_{2} \mathrm{~S}$ clinker was ground into two particle sizes, one to pass a 325 mesh (maximum size $45 \mu \mathrm{m}$ ) and the other to pass a 100 mesh (maximum size 100 $\mu \mathrm{m})$. These powders are denoted S2 and $\mathrm{S} 1$, where the $\mathrm{S}$ denotes the standard method of manufacture. 


\begin{tabular}{lcc} 
Sample & $\begin{array}{c}\text { Average grain size } \\
(\mu \mathrm{m})\end{array}$ & $\begin{array}{c}\text { Max grain size } \\
(\mu \mathrm{m})\end{array}$ \\
\hline S1 & - & 100 \\
S2 & - & 45 \\
R1000 & 2 & - \\
R800 & 0.07 & -
\end{tabular}

Table 1: $\mathrm{C}_{2} \mathrm{~S}$ sample ID and corresponding characteristic grain size.

In addition, two batches of $\beta-\mathrm{C}_{2} \mathrm{~S}$ were made using the sol-gel Pechini method $[9,10,11]$ that results in powders with much higher surface area and reactivity. Stoichiometric mixtures of calcium nitrate hydrate, $\mathrm{Ca}\left(\mathrm{NO}_{3}\right)_{2} \cdot \mathrm{H}_{2} \mathrm{O}$, ( $\geq 99.0 \%$, Fisher Scientific) and colloidal $\mathrm{SiO}_{2}$ (Ludox AS-40, Sigma Aldrich) were incorporated into a resin matrix prepared from $60 \mathrm{wt} \%$ citric acid monohydrate (Fisher Scientific) and 40 wt\% ethylene glycol (Fisher Scientific). Calcium nitrate hydrate $(\mathrm{CNH})$ was dissolved in de-ionised water which was then mixed with pre-acidified $\mathrm{SiO}_{2}$ aqueous solution ( $\mathrm{pH} 1.5$ achieved using $\mathrm{HNO}_{3}$ ). In a separate mix, citric acid mono-hydrate $(\mathrm{CCH})$ was mixed with ethylene glycol (EG) in the presence of water. Thereafter, the precursor solution containing silica nanoparticles and $\mathrm{CNH}$ was mixed with CCH-EG aqueous solution. The mixture was stirred for 30 minutes and then heated at $90^{\circ} \mathrm{C}$ until a highly viscous gel product was formed. The resultant gel was dried at $90^{\circ} \mathrm{C}$, and the remaining solid was ground and further heated at $220^{\circ} \mathrm{C}$ for 3 hours. Finally, the solid was calcined at either $800^{\circ} \mathrm{C}$ or $1000{ }^{\circ} \mathrm{C}$, resulting in two powders denoted R800 and R1000, respectively. The BET surface areas of R800 andR1000 are $26.5 \mathrm{~m}^{2} \mathrm{~g}^{-1}$ and $8.3 \mathrm{~m}^{2} \mathrm{~g}^{-1}$ respectively, corresponding to average grain diameters of $0.07 \mu \mathrm{m}$ and $0.22 \mu \mathrm{m}$ (assuming spherical grains and $\mathrm{C}_{2} \mathrm{~S}$ density of $\left.3.28 \mathrm{~g} \mathrm{~cm}^{-3}\right)$.

The X-ray diffraction (XRD) patterns for the different types of $\mathrm{C}_{2} \mathrm{~S}$ are shown in Fig. 1, with some distinctive peaks of the $\beta$ polymorph labeled. A PANalytical X'Pert Pro X-ray diffractometer was used, operating at $40 \mathrm{kV}$ with 40 $\mathrm{mA}$, fixed divergence slit with slit size $1^{\circ}$, and step size of $0.033^{\circ}$ with 2 seconds per step. The X-ray wavelengths were for $\mathrm{Cu} . \mathrm{K} \alpha$ radiation $\left(\mathrm{Cu} . \mathrm{K} \alpha_{1}=1.54060\right.$ 


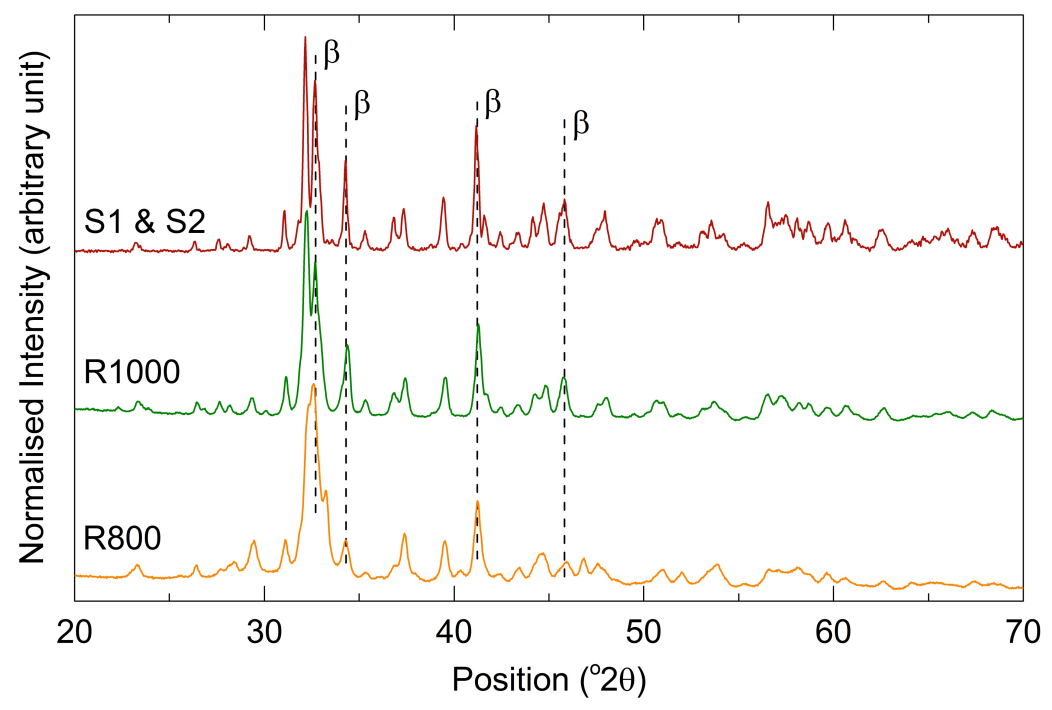

Fig. 1: X-ray diffraction patterns for the different $\mathrm{C}_{2} \mathrm{~S}$ powders.

$\AA$, Cu.K $\alpha_{2}=1.5443 \AA$ and $\left.\alpha_{1} / \alpha_{2}=0.5\right)$. The patterns in Fig. 1 show that all the samples were well calcined to produce $\mathrm{C}_{2} \mathrm{~S}$, with no unexpected peaks or evidence of unreacted phases. The patterns for the standard powder $\left(S_{1} / S_{2}\right)$ and for reactive powder R1000 are indicative of $\beta-\mathrm{C}_{2} \mathrm{~S}$, without evidence of other $\gamma$ or $\alpha$ polymorphs $[22,10]$. The R800 powder also displays a similar pattern, although the $\beta$-specific peaks are slightly less pronounced. This may indicate a lower level of crystallinity in this sample.

\section{2. $C_{2} S$ pastes}

When mixing some samples, a 0.5 M sodium metasilicate (NaSi) solution was used in place of the mix water. This solution was prepared prior the the experiment by dissolving granules of technical grade $\mathrm{Na}_{2} \mathrm{O} \cdot \mathrm{iO}_{2} \cdot 5 \mathrm{H}_{2} \mathrm{O}$ in water. In some cases, $\mathrm{C}-\mathrm{S}-\mathrm{H}$ seed with a $\mathrm{Ca} / \mathrm{Si}$ molar ratio of 1 was added to the paste. The seed material was prepared by precipitation from calciuSm nitrate and sodium metasilicate solutions, rinsed and filtered to form a thick gel as detailed in Ref. [19]. The solids content of the resulting seed, measured by the weight loss on heating to $100^{\circ} \mathrm{C}$, was $6 \%$ by weight. The seed was added to 
pastes in the amount of $2 \%$ solid $\mathrm{C}-\mathrm{S}-\mathrm{H}$ by mass of $\mathrm{C}_{2} \mathrm{~S}$. The evaporable water present in the seed resulted in an increase in the effective water-to-cement mass ratio (w/c) of the paste, as the amount of mix water or NaSi solution was kept fixed.

Pastes were mixed by hand in a small ceramic crucible. The w/c required to make a workable paste varied with the batch of $\mathrm{C}_{2} \mathrm{~S}$ because the use of reactive powder with a high surface area greatly increases the water demand. For the standard $\mathrm{C}_{2} \mathrm{~S}$ powders, the w/c was 0.5 . For the reactive $\mathrm{C}_{2} \mathrm{~S}$ fired at $1000^{\circ} \mathrm{C}$, the w/c was 1.6 , and for the reactive $\mathrm{C}_{2} \mathrm{~S}$ fired at $800^{\circ} \mathrm{C}$ the w/c was 2 . While the $\mathrm{w} / \mathrm{c}$ can have an effect on the hydration kinetics, this effect is generally rather small [23].

\subsection{Calorimetry}

The calorimetric tests were conducted using a differential scanning calorimeter (MC-DSC, TA Instruments). This intrument has stable baseline heat flow that makes it suitable for accurate measurements of isothermal heat output, while also allowing the temperature to be changed and restabilized in approximately 30 minutes. The latter feature makes it feasible to conduct repeated activation energy measurements during a single run, as discussed in detail in [21]. The samples were loaded in the machine's stainless steel cells and sealed with O-rings. Approximately $1.4 \mathrm{~g}$ of paste was used in each test.

To estimate the degree of hydration, we divide the hydration heat by the hydration enthalpy for $\beta-\mathrm{C}_{2} \mathrm{~S}$ of $-262 \mathrm{~J} / \mathrm{g}$ [22]. In the pastes made with sodium silicate solution, the product formation will be altered to form more $\mathrm{C}-\mathrm{S}-\mathrm{H}$ instead of $\mathrm{CH}$, which could change the enthalpy. However, the heat signal is dominated by the dissolution of the mineral (see e.g. calculations in [24]), so a slight change in the type of products formed will have a small effect, which we neglect.

The apparent activation energy $E_{a}$ of hydration has been computed after each change of temperature, using the following equation as detailed in Ref. [21]:

$$
E_{a}=R\left[\frac{T_{1} T_{2}}{T_{1}-T_{2}} \ln \left(\frac{I_{1}}{I_{2}}\right)\right],
$$



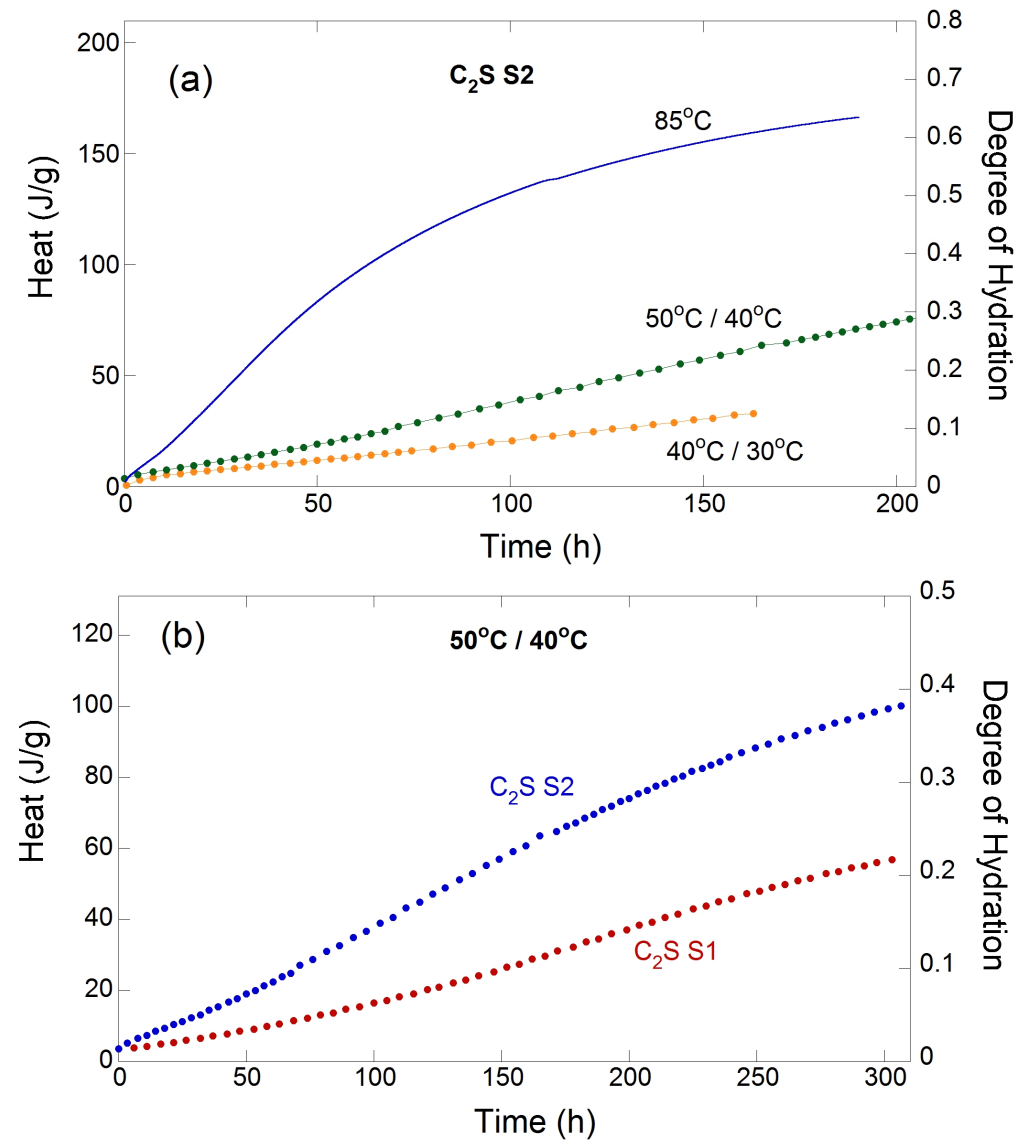

Fig. 2: Cumulative heat and corresponding degree of hydration for neat pastes made with standard $\mathrm{C}_{2} \mathrm{~S}$ powder. Dual temperature runs indicate hydration with temperature alternating between the two values in equal time increments. a) Powder S2 hydrated at different temperatures. b) Powders S2 and S1 compared under the same temperature condition.

where $R$ is the gas constant and $I_{1}$ and $I_{2}$ are the rates of heat evolution at temperatures $T_{1}$ and $T_{2}$ respectively.

\section{Results}

\subsection{Neat $\beta-C_{2} S$ : hydration kinetics}

The cumulative heat evolution of neat $\mathrm{C}_{2} \mathrm{~S}$ paste made from the finer standard sample S2 at different temperatures is shown in Fig. 2(a). Runs denoted 
$50^{\circ} \mathrm{C} / 40^{\circ} \mathrm{C}$ and $40^{\circ} \mathrm{C} / 30^{\circ} \mathrm{C}$ were conducted by alternating between the two temperatures in $3.5 \mathrm{~h}$ increments, while the $85^{\circ} \mathrm{C}$ run was isothermal. As expected, hydration is quite slow compared to $\mathrm{C}_{3} \mathrm{~S}$ or portland cement. Only at the significantly elevated temperature of $85^{\circ} \mathrm{C}$ is a reasonable degree of hydration achieved after 200 hours of hydration. Comparison of the two standard $\mathrm{C}_{2} \mathrm{~S}$ samples at the same temperature appears in Fig. 2(b). The S1 powder hydrates more slowly than the S2 powder, as expected from its larger particle size. The remaining experiments with standard $\mathrm{C}_{2} \mathrm{~S}$ will focus on the $\mathrm{S} 2$ powder because it gives a higher signal to noise ratio at given temperature than the S1 powder, and thus better quality data.

Cumulative heat evolution for reactive $\mathrm{C}_{2} \mathrm{~S}$ pastes is shown in Fig. 3 at $30^{\circ} \mathrm{C}$ and $85^{\circ} \mathrm{C}$. The powder fired at $800^{\circ} \mathrm{C}(\mathrm{R} 800)$ is much more reactive than the standard $\mathrm{C}_{2} \mathrm{~S}$ powders shown in Fig. 2. At $85^{\circ} \mathrm{C}$, the $\mathrm{R} 800$ powder is nearly fully reacted in less than $10 \mathrm{~h}$. The powder fired at $1000^{\circ} \mathrm{C}(\mathrm{R} 1000)$ is significantly less reactive than powder $\mathrm{R} 800$, though it is still more reactive than powder $\mathrm{S} 2$.

\subsection{Neat $\beta-C_{2} S$ : activation energies}

The calorimetry runs conducted with alternating temperatures were used to calculate the apparent activation energy as a function of time. The results of two such runs, conducted at different temperatures, are shown in Fig. 4 for the standard $\mathrm{S}_{2} \mathrm{C}_{2} \mathrm{~S}$. For both of these runs, the activation energy is constant throughout the hydration period with a value of about $32 \mathrm{~kJ} / \mathrm{mol}$. For the hydration periods shown, the degree of hydration reaches about 0.3 for the $50^{\circ} \mathrm{C} / 40^{\circ} \mathrm{C}$ run and about 0.35 for the $85^{\circ} \mathrm{C} / 72^{\circ} \mathrm{C}$ run. The signal to noise ratios became too low for accurate calculation of the activation energy after that point.

Activation energy results for the reactive $\mathrm{C}_{2} \mathrm{~S}$ powders are shown in Fig. 5 . For both the R800 and R1000 powders, the activation energy is quite constant with time, as with the standard powder, but with a higher value of about 55 $\mathrm{kJ} / \mathrm{mol}$. This large difference in activation energy for the standard and reactive powders suggests that the rate controlling mechanisms are different in these two 

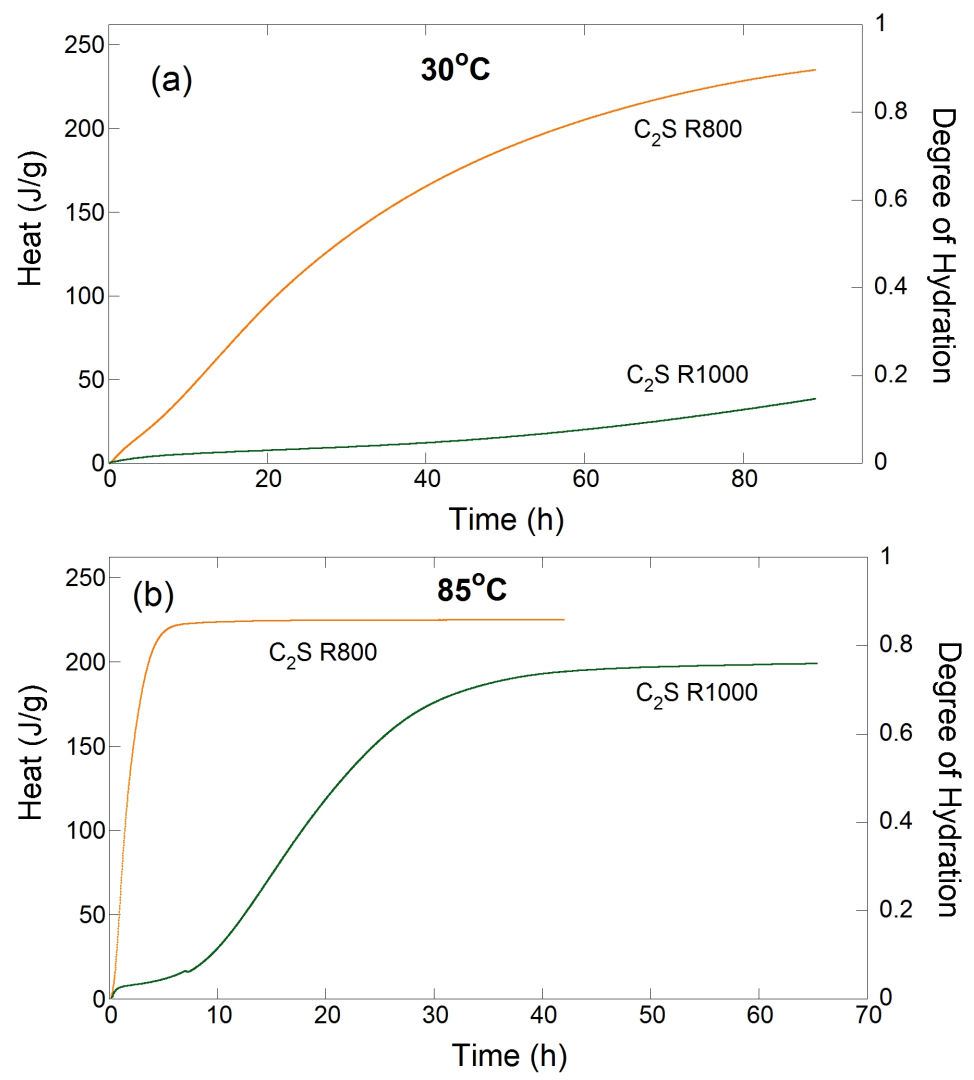

Fig. 3: Cumulative heat and corresponding degree of hydration for neat pastes made with the two reactive $\mathrm{C}_{2} \mathrm{~S}$ powders. a) Isothermal at $30^{\circ} \mathrm{C}$. b) Isothermal at $85^{\circ} \mathrm{C}$.

cases. Interestingly, the higher value obtained for reactive $\mathrm{C}_{2} \mathrm{~S}$ is similar to the value of $E_{a}=52 \mathrm{~kJ} / \mathrm{mol}$ previously determined by the same method for neat and $\mathrm{CaCl}_{2}$-accelerated tricalcium silicate pastes [21]; the implications of this observation are discussed in the next section.

\subsection{Effect of NaSi and $C-S-H$ on hydration of standard $\beta-C_{2} S$}

The effects of NaSi and combined addition of NaSi and C-S-H on the hydration kinetics of the $\mathrm{S} 2$ standard $\beta-\mathrm{C}_{2} \mathrm{~S}$ with the temperature alternated between $40^{\circ} \mathrm{C}$ and $30^{\circ} \mathrm{C}$ are shown in Fig. 6. The most obvious effect of the additives is the generation of sharp rate peaks (Fig. 6a), which are not observed for the 

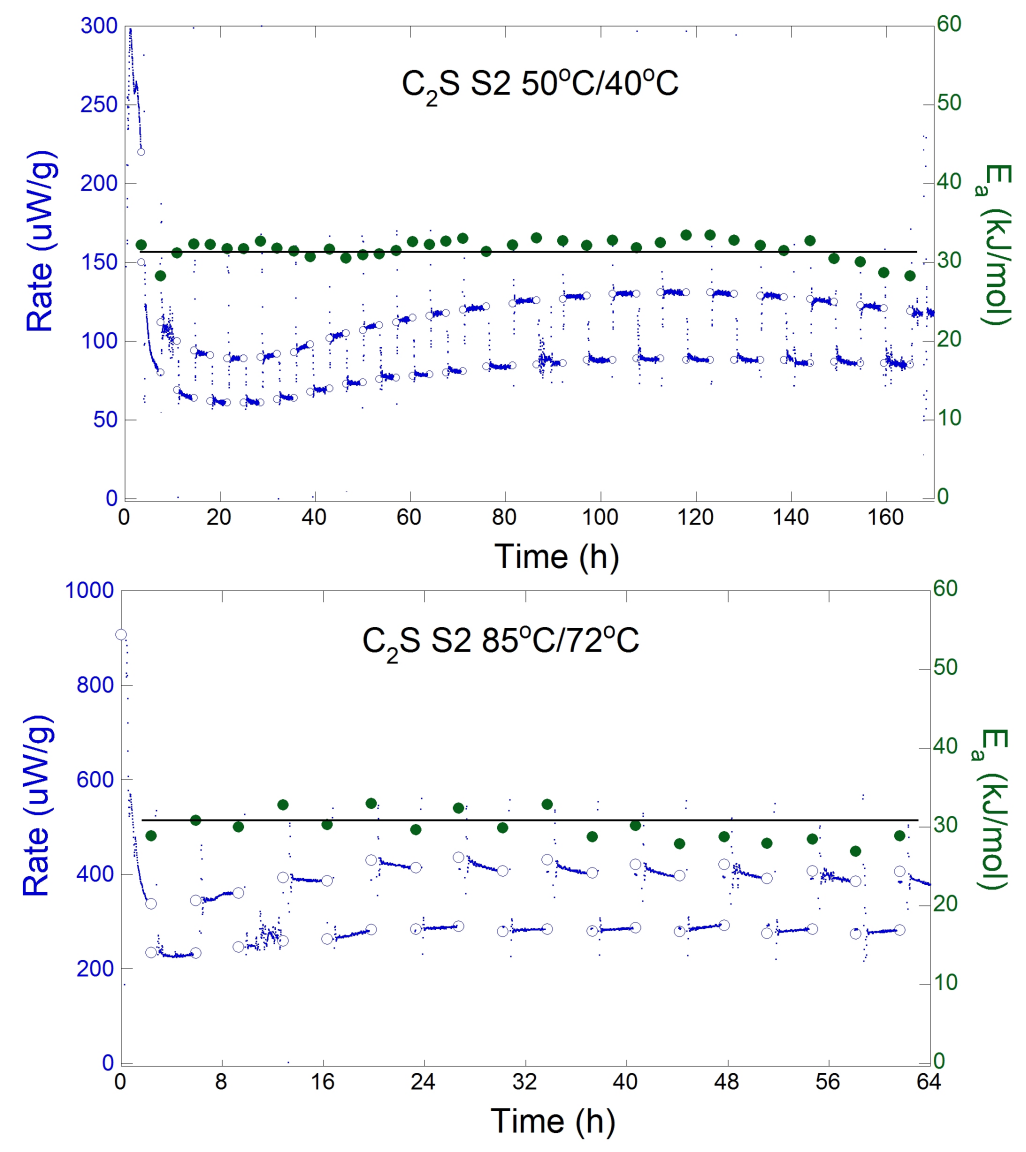

Fig. 4: Activation energy experiments for neat paste made with standard $\mathrm{C}_{2} \mathrm{~S}$ powder $\mathrm{S} 2$. The hydration rate is plotted on the left axis, and the corresponding activation energy values are plotted on the right axis. Top: Temperatures of $50^{\circ} \mathrm{C}$ and $40^{\circ} \mathrm{C}$. Bottom: Temperatures of $85^{\circ} \mathrm{C}$ and $72^{\circ} \mathrm{C}$. The small open circles are the extrapolated rates used to calculate the activation energy values at a given time. The horizontal black lines are guides to the eye.

neat paste. In the presence of only $\mathrm{NaSi}$, the rate peak does not appear until more than $20 \mathrm{~h}$ after mixing, while in the presence of both $\mathrm{NaSi}$ and $\mathrm{C}-\mathrm{S}-\mathrm{H}$ the peak occurs immediately after mixing. From the cumulative heat results plotted in Fig. 6b it can be seen that addition of NaSi without C-S-H causes the hydration rate before and after the rate peak to be lower than that of the neat paste. This causes the degree of hydration of $\mathrm{C}_{2} \mathrm{~S}$ with NaSi to become lower than that of neat $\mathrm{C}_{2} \mathrm{~S}$ after $\sim 100$ hours. The NaSi solution therefore acts 

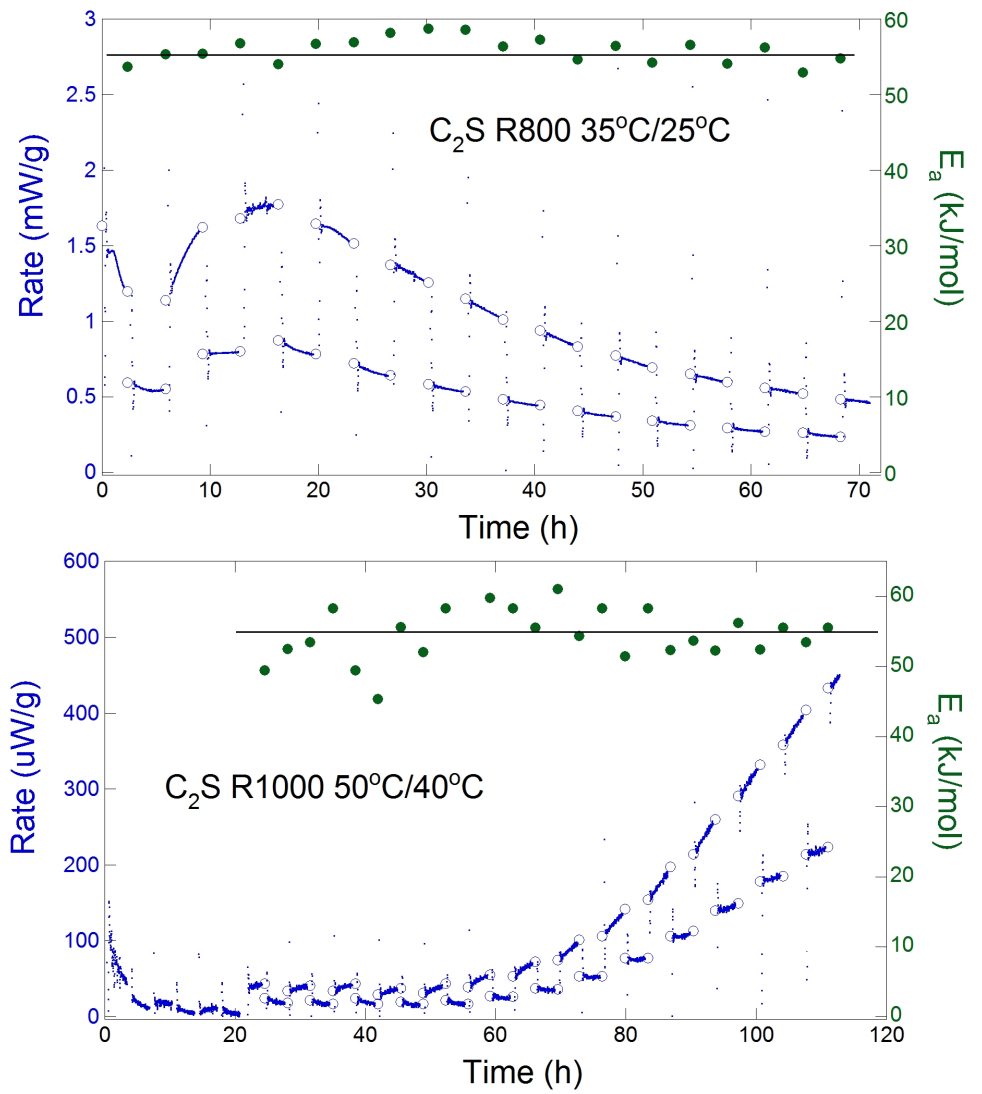

Fig. 5: Activation energy experiment for neat paste made with reactive $\mathrm{C}_{2} \mathrm{~S}$ powders $\mathrm{R} 800$ (top) and R1000 (bottom). The horizontal black lines are guides to the eye. For the R1000 powder, there was not enough signal to calculate the activation energy until after $24 \mathrm{~h}$.

generally as a retarder except during a sharp and short-lived rate peak.

Adding both $\mathrm{C}-\mathrm{S}-\mathrm{H}$ and NaSi generates an immediate acceleration, eliminating the induction period seen with NaSi only and leading to a hydration degree that is greater than that of the neat and NaSi-only pastes during at least the first week of hydration, although the higher degree of hydration is nearly lost after one week of hydration at $40^{\circ} \mathrm{C}$ and $30^{\circ} \mathrm{C}$ (see Fig. $6 \mathrm{~b}$ ).

At $85^{\circ} \mathrm{C}$, the degree of hydration after one week is significantly higher for all paste types, but similar effects of the additives are seen (Fig. 6c). Addition 

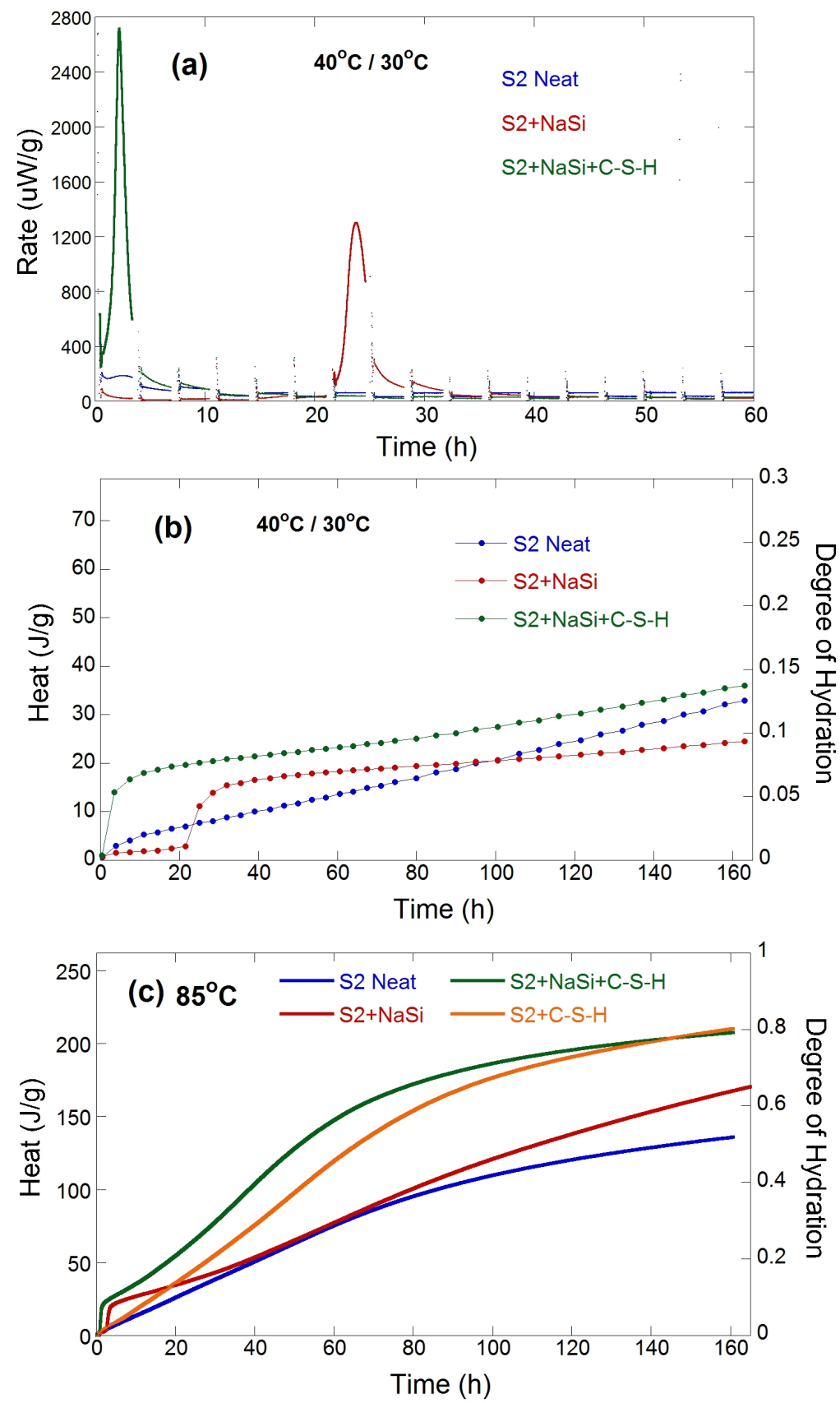

Fig. 6: Hydration of standard $\beta-\mathrm{C}_{2} \mathrm{~S}$ powder $\mathrm{S} 2$ with addition of $\mathrm{NaSi}$ and $\mathrm{C}-\mathrm{S}-\mathrm{H}$. (a) Hydration rate with temperature alternated between $40^{\circ} \mathrm{C}$ and $30^{\circ} \mathrm{C}$; (b) Cumulative heat and degree of hydration for the same runs (note different time scale). (c) Cumulative heat and degree of hydration for isothermal hydration at $85^{\circ} \mathrm{C}$ 
of NaSi causes a small, sharp increase in the cumulative heat after only about 1 hour. After this time the heat evolved remains similar at all times to the neat paste, with no long-term retarding effect. Addition of $\mathrm{C}-\mathrm{S}-\mathrm{H}$ to the paste, with or without $\mathrm{NaSi}$, significantly increases the degree of hydration during the first week of hydration. While the addition of both NaSi and C-S-H causes the greatest early acceleration, the paste with only $\mathrm{C}-\mathrm{S}-\mathrm{H}$ reaches an equal degree of hydration of about 0.80 after one week.

Fig. 7 shows the results of activation energy experiments on pastes made with $\mathrm{S} 2 \mathrm{C}_{2} \mathrm{~S}$ powder and hydrated with $\mathrm{NaSi}$ and with both $\mathrm{NaSi}$ and $\mathrm{C}-\mathrm{S}-\mathrm{H}$. Addition of NaSi results in two distinct activation energy regimes (Fig. 7, top). Prior to and during the rate peak, the $E_{a}$ value is $\approx 50 \mathrm{~kJ} / \mathrm{mol}$. As the peak ends, the activation energy drops sharply to $\approx 32 \mathrm{~kJ} / \mathrm{mol}$ and remains at this value thereafter. The initial higher value is similar to the value obtained for reactive $\mathrm{C}_{2} \mathrm{~S}$ (see Fig. 5), while the later, lower value is similar to that obtained for neat standard $\mathrm{C}_{2} \mathrm{~S}$ paste (see Fig. 4).

Similar behavior is observed for the paste made with both $\mathrm{NaSi}$ and $\mathrm{C}-$ S-H (Fig. 7, bottom). In this case, however. the rate peak occurs almost immediately after mixing and only one measurement of the higher activation energy was obtained. The large change in the activation energy is evidence that the rate-controlling step changes during the hydration process.

\subsection{Effects of $\mathrm{NaSi}$ and $\mathrm{C}-\mathrm{S}-\mathrm{H}$ on hydration of reactive $\beta-\mathrm{C}_{2} S$}

Fig. 8 shows the effects of NaSi and $\mathrm{C}-\mathrm{S}-\mathrm{H}$ on the cumulative hydration of reactive $\mathrm{C}_{2} \mathrm{~S}$ powder $\mathrm{R} 800$ hydrated at alternating temperatures of $35^{\circ} \mathrm{C}$ and $25^{\circ} \mathrm{C}$. The addition of NaSi has a strong accelerating effect, causing a significant increase in the amount of hydration occurring in the first several hours. The addition of $\mathrm{C}-\mathrm{S}-\mathrm{H}$ has a more modest, but measurable effect, increasing the degree of hydration slightly both with and without the presence of NaSi.

The results of the activation energy experiments for the R800 powder hydrated with $\mathrm{NaSi}$ and $\mathrm{C}-\mathrm{S}-\mathrm{H}$ are shown in Fig. 9. These are the same experiments from which the cumulative heat data plotted in Fig. 8 were obtained. 

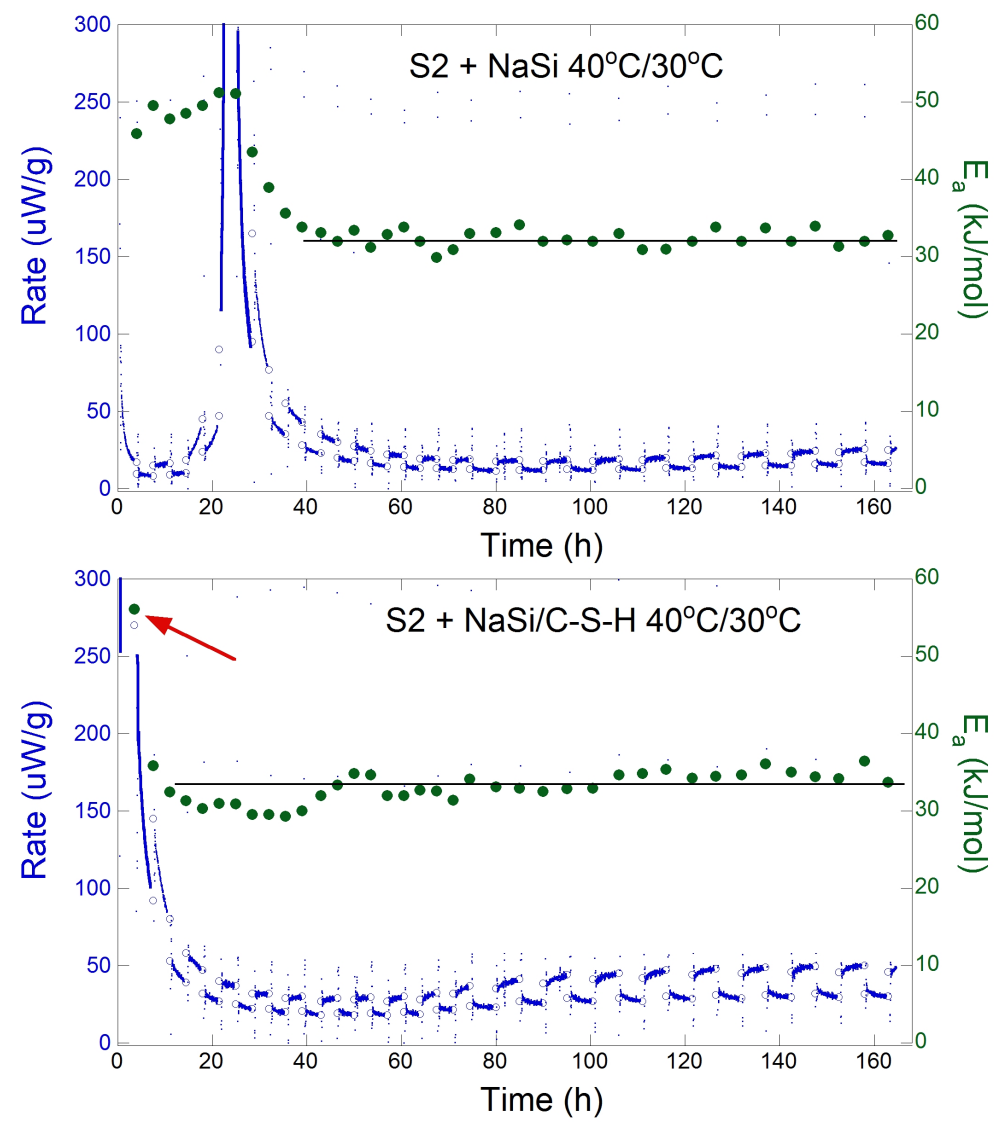

Fig. 7: Activation energy results for pastes made with standard $\mathrm{C}_{2} \mathrm{~S}$ powder $\mathrm{S} 2$ with addition of $\mathrm{NaSi}$ (top) and addition of both $\mathrm{NaSi}$ and $\mathrm{C}-\mathrm{S}-\mathrm{H}$ (bottom). In both experiments the temperature was alternated between $40^{\circ} \mathrm{C}$ and $30^{\circ} \mathrm{C}$. The horizontal black lines are guides to the eye. Note the higher first activation energy value marked with an arrow in the bottom plot.

With the addition of only $\mathrm{C}-\mathrm{S}-\mathrm{H}$ (Fig. 9(a)), the activation energy remains constant at about $55 \mathrm{~kJ} / \mathrm{mol}$, as with the neat paste experiment (see Fig. 5). For the pastes made with NaSi (Fig. 9(b)) and with both $\mathrm{NaSi}$ and $\mathrm{C}-\mathrm{S}-\mathrm{H}$ (Fig. 9(c))) the result is somewhat different. The activation energy starts out quite high, but then declines gradually after about $24 \mathrm{~h}$, reaching a value of about $40 \mathrm{~kJ} / \mathrm{mol}$ after $70 \mathrm{~h}$. This suggests that the addition of NaSi has some effect on the rate-controlling step for the hydration of this powder. 


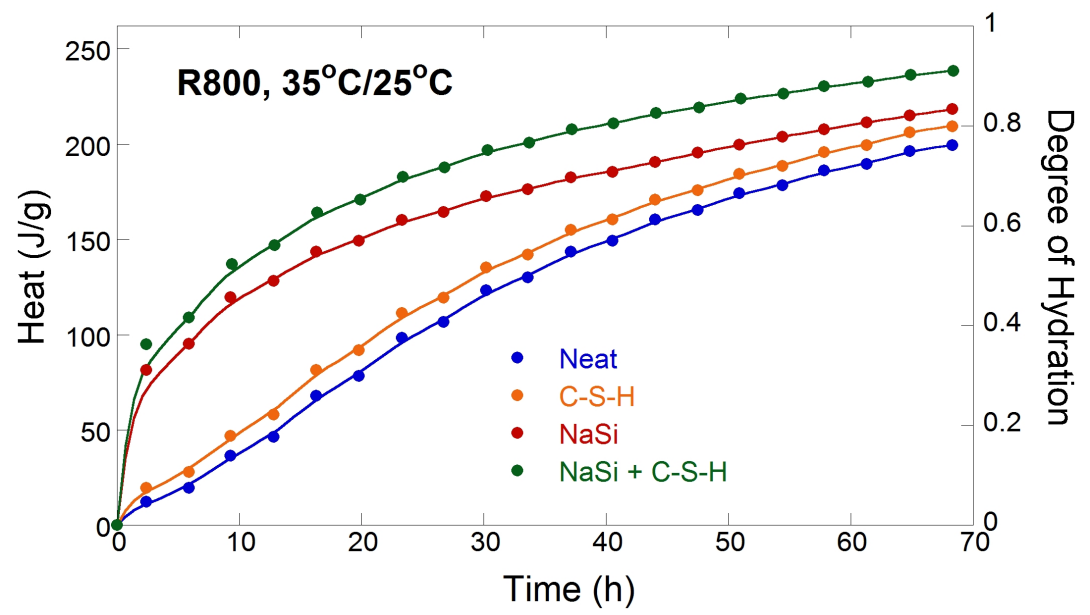

Fig. 8: Cumulative heat and degree of hydration of reactive $\beta-\mathrm{C}_{2} \mathrm{~S}$ powder R 800 with addition of $\mathrm{NaSi}$ and $\mathrm{C}-\mathrm{S}-\mathrm{H}$, hydrated with temperature alternated between $35^{\circ} \mathrm{C}$ and $25^{\circ} \mathrm{C}$.

\section{Discussion}

\subsection{Hydration of standard $\beta-C_{2} S$}

We first consider the behavior of the standard $\mathrm{C}_{2} \mathrm{~S}$, which is more similar to the belite found in cement. For the neat paste, the activation energy $E_{a}$ is about $32 \mathrm{~kJ} / \mathrm{mol}$. This is significantly lower than the value previously measured for $\mathrm{C}_{3} \mathrm{~S}$ of $52 \mathrm{~kJ} / \mathrm{mol}$ using the same technique [21]. It is interesting to note that the activation energy of Portland cement always falls between these values, whether measured by traditional maturity-type methods $[25,26]$ or by the instantaneous method used here [21]. This is the expected result, given that $\mathrm{C}_{3} \mathrm{~S}$ and $\mathrm{C}_{2} \mathrm{~S}$ are reacting simultaneously. The contribution to the overall activation energy of cement will depend on the amount of each mineral present, the hydration rate of each mineral, and on the enthalpy of the mineral. All of these factors favor the cement activation energy during the first several days of hydration being closer to that of $\mathrm{C}_{3} \mathrm{~S}$ than $\mathrm{C}_{2} \mathrm{~S}$.

The addition of $0.5 \mathrm{M} \mathrm{NaSi}$ to standard $\mathrm{C}_{2} \mathrm{~S}$ paste causes the delayed formation of a short, sharp hydration peak and a much higher activation energy until the peak is ending, after which $E_{a}$ returns to the neat paste value. To 

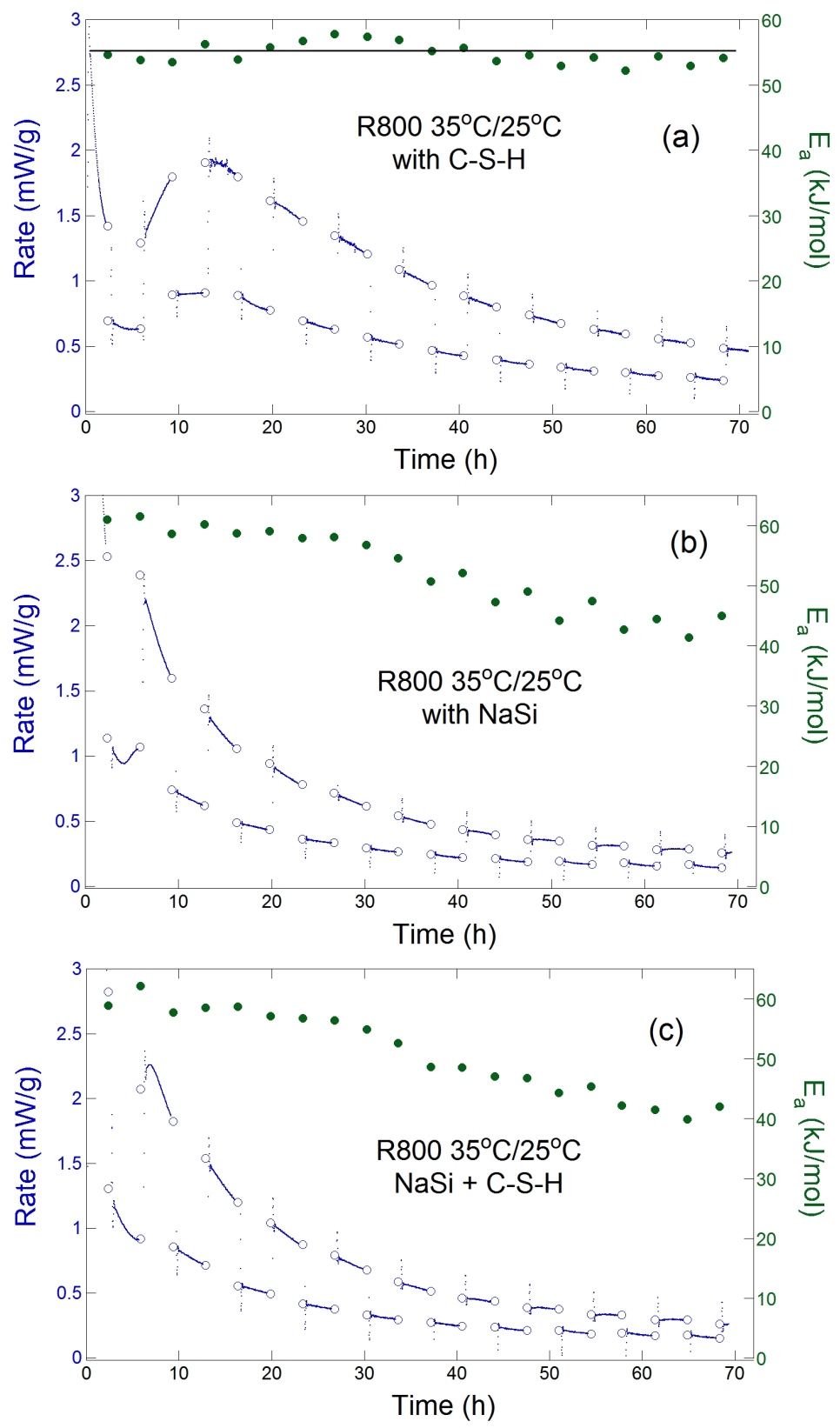

Fig. 9: Activation energy results for accelerated pastes made with reactive $\mathrm{C}_{2} \mathrm{~S}$ powders $\mathrm{R} 800$ and hydrated at $35^{\circ} \mathrm{C}$ and $25^{\circ} \mathrm{C}$. a) With $\mathrm{C}-\mathrm{S}-\mathrm{H}$ only. The horizontal black line is a guide to the eye. b) With NaSi only. c) With NaSi and C-S-H. 
our knowledge, this is the first direct measurement of a change in the activation energy during a hydration reaction. It seems logical to assume that this change in activation energy results from a change in the rate controlling step for the reaction.

We hypothesize that the early higher $\mathrm{C}_{2} \mathrm{~S}$ activation energy is associated with nucleation and growth $(\mathrm{N}+\mathrm{G})$ rate control; that is, the process of hydration products precipitating out of the solution. This is generally accepted to be the rate controlling step for early $\mathrm{C}_{3} \mathrm{~S}$ hydration $[27,28]$, so this hypothesis is supported by the fact that the activation energies are similar, as the hydration products $\left(\mathrm{C}-\mathrm{S}-\mathrm{H}\right.$ and portlandite) are the same for $\mathrm{C}_{2} \mathrm{~S}$ and $\mathrm{C}_{3} \mathrm{~S}$ hydration (albeit in different proportions).

The lower activation energy at later times in the presence of $\mathrm{NaSi}$ (and at all times in the neat standard $\mathrm{C}_{2} \mathrm{~S}$ paste) could therefore be associated with either dissolution control or diffusion control (there are no other options that we are aware of). While a transition to a diffusion-controlled reaction was once considered the standard explanation for the slowing of the hydration rate of $\mathrm{C}_{3} \mathrm{~S}$ and cement at later times, this interpretation has now fallen out of favor [28]. We therefore hypothesize that the lower value of about $32 \mathrm{~kJ} / \mathrm{mol}$ represents the activation energy for $\mathrm{C}_{2} \mathrm{~S}$ dissolution. This is also supported by previous work indicating that the aqueous solution of a standard $\beta-\mathrm{C}_{2} \mathrm{~S}$ paste approaches equilibrium with the $\mathrm{C}-\mathrm{S}-\mathrm{H}$ hydration product during the first hours of hydration [29]. In general, activation energies for aqueous dissolution of minerals vary rather widely. Reported values for several oxide and hydroxide minerals as tabulated in [30] range from $19-86 \mathrm{~kJ} / \mathrm{mol}$, so the presently reported value of $32 \mathrm{~kJ} / \mathrm{mol}$ could be considered typical.

With this interpretation it is tempting to conclude that the NaSi solution increases the dissolution rate of the $\mathrm{C}_{2} \mathrm{~S}$, by analogy to the hydration of slag, where the dissolution is promoted by high $\mathrm{pH}$. However, if this were the case, the hydration should be accelerated, whereas during the early period when the measured activation energy is higher the paste with NaSi is actually hydrating more slowly than the neat paste (see Fig. 6). Therefore, we conclude that the 
NaSi solution temporarily slows the rate of $\mathrm{N}+\mathrm{G}$ of product at early times, causing this process to become rate controlling and slowing the overall rate. This effect might arise due to the the initial formation of a layer of hydration product with a low $\mathrm{Ca} / \mathrm{Si}$ ratio on the particle surfaces that prevents further nucleation of product. This retardation ends abruptly with a sharp hydration peak, and the activation energy returns to the lower value that we associate with dissolution control. Thus the effect of NaSi seems to change abruptly from retarding to accelerating. The accelerating effect could result from the reaction of calcium and silicate ions to form $\mathrm{C}-\mathrm{S}-\mathrm{H}$ away from the particle surfaces, providing additional nucleation sites as with $\mathrm{C}-\mathrm{S}-\mathrm{H}$ seeding. The acceleration is short-lived, however, because once the growth rate increases the hydration process quickly becomes dissolution controlled due to the low solubility of the $\mathrm{C}_{2} \mathrm{~S}$.

The effect of adding C-S-H seed to standard $\mathrm{C}_{2} \mathrm{~S}$ paste made with NaSi supports the hypothesis that NaSi solution initially suppresses nucleation on the particle surfaces. With both $\mathrm{C}-\mathrm{S}-\mathrm{H}$ and NaSi, the period of slower hydration rate prior to the peak is eliminated, and the peak occurs directly after mixing. $\mathrm{C}-\mathrm{S}-\mathrm{H}$ provides nucleation sites, accelerating a process that is controlled by $\mathrm{N}+\mathrm{G}$. In this case, only one measurement of the higher (N+G-controlled) activation energy was obtained before the value returned to dissolution control.

Addition of $\mathrm{C}-\mathrm{S}-\mathrm{H}$ gel only to standard $\mathrm{C}_{2} \mathrm{~S}$ paste at $85^{\circ} \mathrm{C}$ has an overall accelerating effect (see Fig. 6c). The degree of hydration increases steadily with respect to the neat paste throughout the entire week of the measurement (Fig. 6c). This is not the behavior expected for a seeding effect, which tends to generate most of its accelerating effect early in the hydration process. Also, a seeding effect should not occur for a dissolution-controlled reaction. Instead, we propose that the increased degree of hydration is a microstructural effect. Hydration product tends to form directly on the surface of the hydrating mineral, which can reduce the dissolution rate by decreasing the contact between the mineral and aqueous solution [31]. The addition of $\mathrm{C}-\mathrm{S}-\mathrm{H}$ promotes the formation of hydration product away from the surfaces [19], which would allow 
the dissolution rate at a given degree of hydration to be higher.

\subsection{Hydration of reactive $\beta-C_{2} S$}

Turning to the reactive $\mathrm{C}_{2} \mathrm{~S}$ results, the major finding is that the activation energy for the neat paste is high throughout the hydration process (see Fig. 5). For the more reactive powder R800, the activation energy measurements extend to about $80 \%$ degree of hydration. The value of about $55 \mathrm{~kJ} / \mathrm{mol}$ is quite similar to the higher value obtained at early times with standard $\mathrm{C}_{2} \mathrm{~S}$ hydrated with $\mathrm{NaSi}$, and also to the value obtained previously for $\mathrm{C}_{3} \mathrm{~S}$ hydration. Based on the hypotheses developed above, we conclude that the rate controlling step is $\mathrm{N}+\mathrm{G}$ throughout the hydration process for the reactive $\mathrm{C}_{2} \mathrm{~S}$. Since the lower firing temperature of this material greatly increases the specific surface area, it is straightforward to conclude that the dissolution rate is much greater than for the standard $\mathrm{C}_{2} \mathrm{~S}$, greatly increasing the overall hydration rate and causing the rate controlling step to be $\mathrm{N}+\mathrm{G}$. In this respect, the hydration of the reactive $\mathrm{C}_{2} \mathrm{~S}$ is kinetically similar to $\mathrm{C}_{3} \mathrm{~S}$ hydration.

Whereas the effect of $\mathrm{NaSi}$ on the standard $\mathrm{C}_{2} \mathrm{~S}$ was to first slow the rate and then to accelerate it, for the reactive $\mathrm{C}_{2} \mathrm{~S}$ paste made with $\mathrm{NaSi}$ only a large acceleration is observed (see Fig. 8). It appears that the presence of $\mathrm{NaSi}$ is not able to stifle the early $\mathrm{N}+\mathrm{G}$ in this case. If the retarding mechanism is the formation of a low $\mathrm{Ca} / \mathrm{Si}$ layer as suggested above, then the high surface area of the reactive $\mathrm{C}_{2} \mathrm{~S}$, combined with a faster dissolution rate, may prevent a suppressing layer from forming, at least for the NaSi concentration used here. Therefore, it is only the accelerating effect, through formation of $\mathrm{C}-\mathrm{S}-\mathrm{H}$ away from particle surfaces, that is observed.

For the reactive $\mathrm{C}_{2} \mathrm{~S}$ mixed with NaSi the increase in the degree of hydration compared to the neat paste is more pronounced than with the standard $\mathrm{C}_{2} \mathrm{~S}$. This can be explained by the fact that with the standard $\mathrm{C}_{2} \mathrm{~S}$ the rate-controlling step switches to dissolution control as the hydration rate increases, which limits the accelerating effect. For the reactive material made with NaSi the activation energy also drops from the initial high value (see Fig. 9b and 9c). However, the 
decrease is much more gradual than with the standard $\mathrm{C}_{2} \mathrm{~S}$, and the value only drops to about $40 \mathrm{~kJ} / \mathrm{mol}$ by the time the degree of hydration exceeds $80 \%$. We interpret this as a regime of mixed control where the rates of $\mathrm{N}+\mathrm{G}$ and dissolution are similar.

Based on our conclusion that the hydration of the neat reactive $\mathrm{C}_{2} \mathrm{~S}$ paste is $\mathrm{N}+\mathrm{G}$ controlled, we would expect that the addition of $\mathrm{C}-\mathrm{S}-\mathrm{H}$ alone would accelerate the hydration through a seeding effect, as is observed for cement and $\mathrm{C}_{3} \mathrm{~S}$. Somewhat surprisingly, the addition of $\mathrm{C}-\mathrm{S}-\mathrm{H}$ causes only a minor increase in the degree of hydration (see Fig. 8). While the reason for this is not clear, we hypothesize that because the reactive material is highly agglomorated [10], the $\mathrm{C}-\mathrm{S}-\mathrm{H}$ additive is prevented from being in close proximity to most of the $\mathrm{C}_{2} \mathrm{~S}$ surface. On the other hand, the silica in the NaSi solution contacts the $\mathrm{C}_{2} \mathrm{~S}$ surfaces directly, allowing for a greater accelerating effect.

\section{Conclusions}

The activation energy for hydration of $\beta-\mathrm{C}_{2} \mathrm{~S}$ paste was measured as a function of hydration time using a calorimetric method and was found to depend on the surface area and reactivity of the powder as well as on the addition of sodium

silicate. For neat paste made with standard $\mathrm{C}_{2} \mathrm{~S}$ (calcined at high temperature and with low surface area), the activation energy is approximately $32 \mathrm{~kJ} / \mathrm{mol}$ and is constant with time. For neat paste made with reactive $\mathrm{C}_{2} \mathrm{~S}$ (calcined at lower temperature and with high surface area), the activation energy s about 55 $\mathrm{kJ} / \mathrm{mol}$ and is also constant with time. This large difference in activation energy reflects a difference in the rate-controlling step for the hydration process. We hypothesize that the lower activation energy represents the dissolution of $\mathrm{C}_{2} \mathrm{~S}$, while the higher value represents nucleation and growth of hydration product.

The addition of sodium silicate to standard $\mathrm{C}_{2} \mathrm{~S}$ paste causes the formation of a short, sharp rate peak after several hours of hydration. Prior to and during the rate peak, hydration is retarded and the activation energy is approximately 50 $\mathrm{kJ} / \mathrm{mol}$. After the rate peak the overall degree of hydration is greater than that of the neat paste and the activation energy drops to $32 \mathrm{~kJ} / \mathrm{mol}$. We hypothesize 
that the sodium silicate initially hinders the nucleation and growth of product, causing this step to temporarily control the rate. After the rate peak, the rate controlling step returns to dissolution.

Addition of sodium silicate to paste made with reactive $\mathrm{C}_{2} \mathrm{~S}$ is strongly accelerating. We hypothesize that dissolved silica reacts with calcium ions to form $\mathrm{C}-\mathrm{S}-\mathrm{H}$, which accelerates the hydration through a seeding effect. The activation energy starts at $55 \mathrm{~kJ} / \mathrm{mol}$ but then drops slowly to about $40 \mathrm{~kJ} / \mathrm{mol}$, indicating that the hydration process enters a regime of mixed rate control.

The addition of synthetic C-S-H to pastes made with standard $\mathrm{C}_{2} \mathrm{~S}$ caused a steady increase in the degree of hydration as compared to similar paste without $\mathrm{C}-\mathrm{S}-\mathrm{H}$. This is attributed to a redistribution of the hydration product away from the particle surfaces, which increases the dissolution rate at a given degree of hydration. For paste made with standard $\mathrm{C}_{2} \mathrm{~S}$ and $\mathrm{NaSi}$, addition of $\mathrm{C}-\mathrm{S}-\mathrm{H}$ also eliminated the initial period of retardation, causing the brief rate peak to occur immediately after mixing. This can be attributed to a seeding effect.

Addition of $\mathrm{C}-\mathrm{S}-\mathrm{H}$ to reactive $\mathrm{C}_{2} \mathrm{~S}$ pastes had only a minor accelerating effect, despite our conclusion that the hydration rate is controlled by nucleation and growth. We hypothesize that the highly agglomerated nature of the reactive $\mathrm{C}_{2} \mathrm{~S}$ powder prevents the $\mathrm{C}-\mathrm{S}-\mathrm{H}$ additive from coming in close proximity to most of the surface area.

\section{References}

[1] C.D. Popescu, M. Muntean, and J.H. Sharp. Industrial trial production of low energy belite cement. Cem. Concr. Compos., 25(7):689-693, 2003.

[2] L. Barcelo, J. Kline, G. Walenta, and E. Gartner. Cement and carbon emissions. Mater. Struct., 47(6):1055-1065, 2014.

[3] Cement Technology Roadmap 2009: Carbon emissions reductions up to 2050. Technical report, International Energy Agency and World Business Council for Sustainable Development, 2009. 
[4] D. N. Huntzinger and T. D. Eatmon. A life-cycle assessment of portland cement manufacturing: Comparing the traditional process with alternative technologies. J. Clean. Prod., 17(7):668-675, 2009.

[5] D. M. Roy and S. O. Oyefesobi. Preparation of very reactive $\mathrm{Ca}_{2} \mathrm{SiO}_{4}$ powder. J. Am. Ceram. Soc., 60(3-4):178-180, 1977.

[6] D. M. Roy, T. P. O'Holleran, and R. R. Neurgaonkar. Preparation and hydration studies of reactive $\beta-\mathrm{Ca}_{2} \mathrm{SiO}_{4}$ prepared by the EDS technique. Cemento, 75(3):337-42, 1978.

[7] N. Yang and B. Zhong. A study on active $\beta$-dicalcium silicate. J. Chin. Silic. Soc, 10(2):161-66, 1982.

[8] H. Ishida, K. Sasaki, and T. Mitsuda. Highly reactive $\beta$-dicalcium silicate: I, Hydration behavior at room temperature. J. Am. Ceram. Soc., $75(2): 353-358,1992$.

[9] I. Nettleship, J. L. Shull, and W. M. Kriven. Chemical preparation and phase stability of $\mathrm{Ca}_{2} \mathrm{SiO}_{4}$ and $\mathrm{Sr}_{2} \mathrm{SiO}_{4}$ powders. J. Europ. Ceram. Soc., 11(4):291-298, 1993.

[10] S.H. Hong and J. F. Young. Hydration kinetics and phase stability of dicalcium silicate synthesized by the Pechini process. J. Am. Ceram. Soc., 82(7):1681-1686, 1999.

[11] Y.-M. Kim and S.-H. Hong. Influence of minor ions on the stability and hydration rates of $\beta$-dicalcium silicate. J. Am. Ceram. Soc., 87(5):900-905, 2004 .

[12] L. Kriskova, Y. Pontikes, F. Zhang, Ö. Cizer, P. T. Jones, K. Van Balen, and B. Blanpain. Influence of mechanical and chemical activation on the hydraulic properties of gamma dicalcium silicate. Cem. Conc. Res., 55:5968, 2014. 
[13] S. Garrault, T. Behr, and A. Nonat. Formation of the CSH layer during early hydration of tricalcium silicate grains with different sizes. J. Phys. Chem. B, 110(1):270-275, 2006.

[14] M. M. Costoya Fernández. Effect of particle size on the hydration kinetics and microstructural development of tricalcium silicate, Ph.D. Thesis, EPFL, 2008.

[15] E. Masoero, J. J. Thomas, and H. M. Jennings. A reaction zone hypothesis for the effects of particle size and water-to-cement ratio on the early hydration kinetics of C3S. J. Am. Ceram. Soc., 97(3):967-975, 2014.

[16] S. N. Ghosh, P. B. Rao, A.K. Paul, and K. Raina. The chemistry of dicalcium silicate mineral. J. Mater. Sci., 14(7):1554-1566, 1979.

[17] J.F. Young and H.-S. Tong. Microstructure and strength development of beta-dicalcium silicate pastes with and without admixtures. Cem. Conc. Res., 7(6):627-636, 1977.

[18] M. J. Sánchez-Herrero, A. Fernández-Jiménez, and Á. Palomo. Alkaline hydration of C2S and C3S. J. Am. Ceram. Soc., 99(2):604-611, 2016.

[19] J. J. Thomas, H. M. Jennings, and J. J. Chen. Influence of nucleation seeding on the hydration mechanisms of tricalcium silicate and cement. $J$. Phys. Chem. C, 113(11):4327-4334, 2009.

[20] M. H. Hubler, J. J. Thomas, and H. M. Jennings. Influence of nucleation seeding on the hydration kinetics and compressive strength of alkali activated slag paste. Cem. Conc. Res., 41(8):842-846, 2011.

[21] J. J. Thomas. The instantaneous apparent activation energy of cement hydration measured using a novel calorimetry-based method. J. Am. Ceram. Soc., 95(10):3291-3296, 2012.

[22] H. F. W. Taylor. Cement chemistry. 1997. 
[23] D. M. Kirby and J. J. Biernacki. The effect of water-to-cement ratio on the hydration kinetics of tricalcium silicate cements: Testing the two-step hydration hypothesis. Cem. Conc. Res., 42(8):1147-1156, 2012.

[24] S. A. Grant, G. E. Boitnott, C. J. Korhonen, and R. S. Sletten. Effect of temperature on hydration kinetics and polymerization of tricalcium silicate in stirred suspensions of CaO-saturated solutions. Cem. Conc. Res., 36(4):671-677, 2006.

[25] A. K. Schindler. Effect of temperature on hydration of cementitious materials. Materials Journal, 101(1):72-81, 2004.

[26] J. L. Poole, K. A. Riding, K. J. Folliard, M. C. G. Juenger, and A. K. Schindler. Methods for calculating activation energy for portland cement. ACI Materials Journal, 104(1):86, 2007.

[27] J. W. Bullard, H. M. Jennings, R. A. Livingston, A. Nonat, G. W. Scherer, J. S. Schweitzer, K. L. Scrivener, and J. J. Thomas. Mechanisms of cement hydration. Cem. Concr. Res., 41:1208-1223, 2011.

[28] K. L. Scrivener, P. Juilland, and P. J.M. Monteiro. Advances in understanding hydration of portland cement. Cem. Conc. Res., 78:38-56, 2015.

[29] P. Barret and D. Bertrandie. Saturated solutions of anhydrous phases in the system lime-silica-water: Example of $\beta$-C2S. J. Am. Ceram. Soc., 73(11):3486-3492, 1990.

[30] J. L. Palandri and Y. K. Kharaka. A compilation of rate parameters of water-mineral interaction kinetics for application to geochemical modeling. Technical report, U.S. Geological Survey, Report 2004-1068, 2004.

[31] J. W. Bullard, G. W. Scherer, and J. J. Thomas. Time dependent driving forces and the kinetics of tricalcium silicate hydration. Cem. Conc. Res., 74:26-34, 2015. 